\section{Violence: the role of society and state}

I question Steven Pinker's optimistic prediction of a continuing decline in interpersonal violence, which is based on supposed correlations of mortality data with improved reasoning ability and IQ (Nature 478, 309-311; 2011).

Even if we disregard possible biases in the mortality data and the problems of quantifying reason and IQ over long time spans or across cultures, a sudden shift in innate individual attributes since the mid-twentieth century is unlikely. Pinker's contention that "modern societies have been getting smarter" makes a further dubious leap from an individual to a social intelligence.

More-concrete social features should be considered. The societies in which the decline of interpersonal violence is most marked have become more organized and affluent, with less contention over resources, and violence has mostly been deferred to the state. We know that this deferral can lead to violent events that are more erratic and severe - and even ideological and irrational.

Primitive terrorism and revenge can be blamed for tens of thousands of casualties in Iraq and Afghanistan. We have had the nuclear technology of violence since the Second World War. Occasions on which nuclear weapons were actually used (with some 200,000 civilian casualties), or were close to being used (in the Korean and Vietnam wars and in Cuba), indicate that the statistics for mortality by violence are unstable owing to the escalation and sensitivity of trigger points.

Rather than an irrational optimism, we should adopt a rational, risk-assessment approach that better recognizes the instability of organized and powerful social violence.
Gary G. Nelson Troy, New York, USA.garygnelson@gmail.com

\section{Violence: intuition is important too}

Steven Pinker argues that humans have been short of rationality throughout most of history, and suggests we may now be putting that right (Nature 478, 309-311; 2011). But intuition - the gut feelings that range from raw instinct to common sense - is important too. Reasoning and intuition together lead to wisdom, but either without the other is dangerous.

Intuition derives from various subconscious responses, presumably largely evolved, that lie at the root of our moral and aesthetic sense. A healthy mind conducts a perpetual dialogue between reasoning and intuition.

Rationality without moral and aesthetic constraint has led us to nuclear war and eugenics and, more recently, to the crude logic of neoliberalism, industrialized agriculture and overconsumption.

This, of course, is where religion comes in. Although it sometimes loses sight of its own raison d'être, its core function is to refine our intuitions.

Colin Tudge Oxford, UK. colin@colintudge.co.uk

\section{Europe must address research misconduct}

In the United States, the Office of Research Integrity and the National Science Foundation both impose legal sanctions for scientific fraud in publicly funded research. The European Commission has no equivalent measures in place. Strict regulations and policy procedures to combat misconduct (see, for example, go.nature.com/a1znzb) are needed before Europe's ambitious Horizon 2020 research-funding programme is introduced in 2014 (Nature 478, 16; 2011).

At present, the programme contains no provision for scientific misconduct. Even the guidelines of the European Code of Conduct for Research Integrity make no detailed recommendations for dealing with fraudulent research (see go.nature.com/juubnq).

Under the Horizon 2020 proposals, grant applicants should sign an ethics declaration confirming that they abide by the European Code of Conduct and will cooperate in and support investigation into suspected violations and alleged misconduct.

Creation of a European agency for research integrity would guarantee that any work funded by Horizon 2020 meets explicit standards. For example, misconduct investigations could be carried out by agency ombudsmen and by ad hoc research-integrity committees, based on the ethics review panels of the current Seventh Framework Programme for research. The agency would listen to whistleblowers and take over investigations impeded by institutional reluctance or by unmanageable conflicts of interest. It could also bar institutions from receiving future grants from the European Commission if they failed to cooperate.

Xavier Bosch Department of Internal Medicine, Hospital Clinic, University of Barcelona, Spain.xavbosch@clinic.ub.es

\section{Caution over Iran's nuclear plans}

Your assertion that the most recent International Atomic Energy Agency's report on Iran's nuclear programme uses "old intelligence" to provide "the sharpest picture yet of the weapon that Iran hopes to develop" (Nature 479, 282; 2011) warrants some contextual explanation.

Some analysts say that this intelligence dates from the turn of the millennium. This is because the latest US National Intelligence Estimates of Iran's nuclear programme (one issued in 2007 and another earlier this year), which represent a consensus of all 16 US intelligence agencies, concluded that Iran ended its efforts to build a nuclear weapon in 2003 (see go.nature.com/ms1sq7).

Many of the same political elements that erroneously claimed that Iraq had nuclear weapons are the ones now insisting that Iran is trying to build a nuclear bomb. This time around, let's be sure of the facts. John W. Grula Carnegie Observatories, Pasadena, California, USA. jgrula@obs.carnegiescience.edu

\section{Canny liars score by tricking themselves}

Robert Trivers makes another significant contribution to evolutionary and behavioural biology in his latest book about deceit and self-deception (Nature 478, 314-315; 2011).

The idea that self-deception is beneficial because it makes it easier to deceive others has also been noted by other observers of human nature. Writer Mark Twain declared: "When a person cannot deceive himself, the chances are against his being able to deceive other people," and author Elizabeth Bear more recently advised: “The secret to getting away with lying is believing with all your heart." Mark A. Davis Macalester College, Saint Paul, Minnesota, USA.davis@macalester.edu

\section{CORRECTION}

Late editorial changes to A. Lescroël and D. Grémillet's Correspondence (Nature 479, 299; 2011) imply that the Ross Sea is already under absolute protection against fishing, which it is not. 